\title{
A PARTICULAR DEVOÇÃO: IMAGINÁRIA, PINTURA E OUTROS OBJECTOS RELIGIOSOS NOS TESTAMENTOS DA ARISTOCRACIA TITULAR DE LISBOA (FINAIS DO SÉC. XVII A FINAIS DO SÉC. XVIII)
}

\author{
SPECIAL DEVOTION: IMAGINARY, PAINTING AND \\ OTHER RELIGIOUS OBJECTS IN THE TESTAMENTS \\ OF THE TITLED ARISTOCRACY OF LISBON (LATE $17^{\mathrm{TH}}$ \\ TO LATE $18^{\mathrm{TH}}$ CENTURIES)
}

\author{
Gonçalo de Vasconcelos e Sousa \\ Universidade Católica Portuguesa. Portugal \\ ORCID: 0000-0002-5776-8163 \\ gvsousa@porto.ucp.pt
}

\begin{abstract}
Los testamentos son una fuente relevante para el estudio de la relación entre la aristocracia de la corte de Lisboa con sus objetos, entre finales del siglo XVII y finales del siglo XVIII. Entre estos, las piezas religiosas son particularmente notables, es decir, referencias a esculturas, pinturas y objetos religiosos. Este análisis constituye un subsidio para la percepción de la devoción, especialmente femenina, en el interior doméstico de este grupo social en la capital portuguesa. Enfatiza el significado y el simbolismo de algunos ejemplos y devociones, evocando gestos de amor expresados en la sucesión de las piezas a las que se hace referencia en esta fuente documental. El origen y la transmisión familiar realizada se cuentan para ciertas piezas.

Palabras clave: escultura; pintura; testamentos; aristocracia; Lisboa.
\end{abstract}

Wills are a relevant source for the study of the relationship between the aristocracy of the Lisbon court with their objects, between the end of the 17th century and the end of the 18th century. Among these, religious pieces are particularly prominent, namely references to sculptures, paintings and other religious objects. This analysis constitutes a subsidy for the perception of devotion, especially female, in the domestic interior of this social group in the Portuguese capital. It highlights the meaning and symbolism of some examples and devotions, evoking gestures of family love expressed in the transmission of the pieces referenced in this documentary source. The origin and the family transmission carried out are explained for certain pieces.

Keywords: sculpture; painting; wills; aristocracy; Lisbon. 


\section{INTRODUÇÃO}

Os testamentos surgem como uma fonte histórica de inegável valor documental, não somente para o estudo do testador, do seu enquadramento pessoal e social, como para aferição de diversos aspectos biográficos do seu percurso pessoal ${ }^{1}$. O seu conteúdo é passível de constituir uma matéria quase inesgotável para estudos históricos, evidenciando-se dimensões económicas, políticas, religiosas, sociais e até artísticas. É neste último domínio que incidirá a nossa leitura, que se vem materializando na realização de várias investigações, relacionando diversos grupos de objectos referenciados ${ }^{2}$.

Para a elaboração deste estudo partimos de uma leitura de cerca de 60 testamentos de titulares existentes no Registo Geral de Testamentos (da zona de Lisboa), núcleo pertencente ao Arquivo Nacional da Torre do Tombo, dos quais seleccionámos um conjunto de 42 documentos com informações referentes a objectos móveis com algum significado. Neste conjunto, a grande maioria foi elaborada por senhoras da corte (30), sobretudo mulheres ou viúvas de titulares e algumas delas até chefes de casa, que se mostravam empenhadas na menção dos bens móveis que as rodeavam e para os quais pretendiam algum tipo de destino mais concreto. Contabilizámos um número mais reduzido de testamentos realizados por aristocratas titulares masculinos (11) e um ainda muito menor de instrumentos de últimas vontades elaborados pelo casal (1). Em concreto para a especificidade deste artigo socorremo-nos apenas de 14 testamentos desse núcleo seleccionado de 43 referenciado supra, pertencendo 12 a senhoras e apenas 2 a homens.

Durante os mais de cem anos analisados, balizados entre o último quartel de Seiscentos e o último quartel do séc. XVIII, os testamentos dos titulares da nobreza cortesã portuguesa revelam, sobretudo os dos membros femininos das famílias, uma religiosidade portas adentro. Esta devoção surge traduzida numa diversidade de pinturas e de imagens de que dispunham nos oratórios ${ }^{3}$ dos seus palácios na capital portuguesa, ou noutras residências de sua propriedade.

Tal materializava-se em representações de Cristo, de Nossa Senhora - nas suas várias invocações - e dos santos de particular devoção, em madeira, marfim, de roca com vestes, entre outros. Também é visível em pinturas e em alfaias

${ }^{1}$ Por exemplo, Sousa, 1997: 75-87.

${ }^{2}$ Para além deste, existem mais três estudos: "Por entre pérolas e pedraria: a joalharia nos testamentos da aristocracia da corte de Lisboa (sécs. XVII e XVIII)" (publicado em Estudios de Platería: San Eloy 2020, pp. 389-400), “Argênteos legados: a prata nos testamentos dos titulares da aristocracia portuguesa (sécs. XVII-XVIII)" e "Móveis e têxteis nos legados testamentários da aristocracia titular da corte portuguesa (sécs. XVII-XVIII)".

${ }^{3}$ Muito explícito desta religiosidade no interior doméstico da casa dos condes de Vila Nova de Portimão, mostra-se o testamento de Francisca Xavier (1780), criada dos ditos titulares. Sousa, 2011: 36 e 40. 
argênteas, demonstrativas dessa religiosidade expressa numa vivência quotidiana da Fé. A eles recorriam nos momentos de grande aflição, agradeciam as graças concedidas e evocavam as memórias e a saudade dos entes queridos que foram partindo.

Em muitos testamentos é passada a escrito a grande afeição que tinham pelos seus objectos religiosos, sendo muito provavelmente essa a razão que os levou a mencioná-los de forma explícita no respectivo testamento. Alguns, como se mostra infra pelas alusões evidenciadas nos documentos, constituem, igualmente, uma ponte para avoengos que partiram e que também eles lhos haviam legado.

\section{UM CONJUNTO DE TESTAMENTOS DE CASAS TITULARES DA CORTE PORTUGUESA}

$\mathrm{Na}$ elaboração deste estudo intervieram elementos retirados de testamentos pertencentes a algumas das mais importantes famílias titulares da corte portuguesa dos finais de Seiscentos até finais de Setecentos ${ }^{4}$. Desde logo, a condessa da Calheta, D. Mariana de Lancastre, que havia sido elevada a marquesa de Castelo Melhor por ser camareira mor da rainha D. Maria Francisca de Nemours, enquanto mulher de D. Afonso VI. Heroína da Guerra da Restauração, o seu marido foi governador-geral do Brasil ${ }^{5}$, vindo esta titular a ser representada, já nos inícios do século XX, nos azulejos de Pereira Cão que decoraram o pátio do Palácio da Rosa, na Mouraria (Lisboa) .

As duas condessas de Pombeiro elencadas neste artigo surgem apartadas por duas gerações. Da primeira, D. Luísa Ponce de Leão, $2 .^{a}$ mulher do $1 .^{\circ}$ conde, D. Pedro de Castelo Branco da Cunha ${ }^{7}$, viria a ser neto o $3 .{ }^{\circ}$ conde deste título, homónimo de seu avô, a quem a titular se refere no seu instrumento de últimas vontades. Era casado segunda vez, sem descendência, com D. Maria Rosa de Noronha $^{8}$, cujo testamento se mencionará, tendo passado depois de viúva a comendadeira de Santos, como se dirá infra.

${ }^{4}$ Sobre as famílias do Antigo Regime, vd. Monteiro, 1998.

${ }^{5}$ Era casada com seu primo, João Rodrigues de Vasconcelos e Sousa, 2. ${ }^{\circ}$ conde de Castelo Melhor (1593-1658). Zúquete, 1984: II, 502-504.

${ }^{6}$ Leal, p. 1034. Por lapso, vem identificada como condessa de Ponte de Lima, título que, aliás, não existe.

${ }^{7}$ Filha de D. Alfonso de Herrera y Cordoba e de sua mulher, D. Luísa Pais de la Cadena Ponce de León. Zúquete, 1984: III, 152-153.

${ }^{8}$ Ou também referenciada como D. Maria Rosa de Portugal, sendo filha dos $10 .^{\text {os }}$ condes de Redondo. Zúquete, 1984: III, 153. 
Os testamentos das condessas de Redondo, D. Madalena Maria de Távora ${ }^{9}$ e D. Maria Antónia de Meneses (1719-1780) ${ }^{10}$, foram elaborados com mais de 65 anos de diferença, sendo a segunda casada com o 12. ${ }^{\circ}$ titular. Quanto aos instrumentos de últimas vontades da marquesa de Montebelo, D. Luísa Maria de Mendonça e Eça ${ }^{11}$, e da condessa de Coculim, D. Maria de Noronha ${ }^{12}$, mulher do $1 .^{\circ}$ conde de Coculim, D. Francisco Mascarenhas (1662-1685), a sua realização data, respectivamente, de 1719 e de 1731 . Outra titular da primeira grandeza do Reino foi, por casamento e nascimento, a marquesa de Cascais, D. Luísa Maria Helena de Noronha, casada com o $3 .^{\circ}$ marquês e $8 .^{\circ}$ conde de Monsanto, D. Manuel José de Castro Noronha Ataíde e Sousa (1666-1742), e possui o testamento redigido em $1753^{13}$.

A condessa da Ribeira Grande, D. Margarida Francisca de Lorena (falecida em 1785), filha dos 2. ${ }^{\text {os }}$ condes de Alvor ${ }^{14}$, revelou-se uma grande impulsionadora do culto do Senhor Santo Cristo. Esta invocação vem mencionada no seu testamento, datado de 1783, como veremos infra, na respectiva análise.

Algumas titulares com testamentos aludindo a objectos religiosos eram senhoras de Casa, como sucedeu com a condessa da Castanheira, D. Ana Ataíde de Castro $^{15}$, e a $2 .^{a}$ marquesa de Penalva, D. Eugénia Mariana Caminha de Meneses (1731-1788) ${ }^{16}$. A primeira não teve descendência, ao contrário da segunda, que teve larga geração de seu primo Manuel Teles da Silva (1727-1789), $6 .^{\circ}$ conde de Vilar Maior.

${ }^{9}$ Filha de António de Mendonça, comendador de Avanca, e de sua mulher, D. Filipa de Távora. O primeiro marido, D. João de Castelo Branco, era filho do $8 .^{\circ}$ conde de Redondo, D. Francisco de Castelo Branco, e sua primeira mulher, D. Isabel de Castelo Branco. O segundo marido, Nuno de Mendonça, era filho de Pedro de Mendonça, alcaide-mor de Mourão e comendador de Santiago de Cacém, e de sua mulher, D. Antónia de Mendoça. Sem geração. Zúquete, 1984: III, 199.

${ }^{10}$ Filha de D. Diogo de Meneses e Távora, senhor da Patameira e de Caparica, e de sua mulher, D. Maria Bárbara Josefa de Breyner. Zúquete, 1984: III, 200.

${ }^{11}$ Filha herdeira de Manuel de Sousa da Silva e de sua mulher, D. Joana de Mendoça, era casada com o 2. ${ }^{\circ}$ marquês de Montebelo, António Félix Machado da Silva e Castro. Zúquete, 1984: III, 26-27.

${ }^{12}$ Filha dos 2. ${ }^{\text {os }}$ marqueses de Nisa. Zúquete, 1984: II, 530-531.

13 Zúquete, 1984: II, 495.

${ }^{14}$ Casada com o $4 .^{\circ}$ conde da Ribeira Grande, D. José da Câmara (1712-1757). Zúquete, 1984: III, 220.

${ }^{15}$ https://arquivodigital.cascais.pt/xarqweb/Result.aspx?id=13655\&type=Autoridade). É comummente referida como D. Ana de Lima e Ataíde.

${ }^{16}$ Filha do $1 .^{\circ}$ marquês de Penalva e $5 .^{\circ}$ conde de Tarouca, D. Estêvão de Meneses, e de sua mulher, D. Margarida de Lorena. Zúquete, 1984: III, 114. 
Neste estudo foram também retiradas notícias de peças religiosas do testamento do vice-rei da Índia (1692-1699) e do Brasil (1714-1718) ${ }^{17}$, D. Pedro António de Noronha de Albuquerque, $1 .^{\circ}$ marquês de Angeja ${ }^{18}$, e do de sua neta, D. Maria Rosa de Noronha, condessa de Castelo Melhor pelo seu casamento ${ }^{19}$. O primeiro documento é datado de 1731 e o outro de 1752, separando-os duas gerações.

Uma última referência é dada ao documento de últimas vontades do $4 .^{\circ}$ conde de S. Miguel, D. Álvaro José Xavier Botelho de Távora (1708-1789) ${ }^{20}$, que revela uma grande minúcia descritiva em relação a numerosos objectos, designadamente peças de natureza religiosa, e de que daremos notícia.

Este breve espectro mostrando uma contextualização social de alguma diversidade, tanto em relação a casas titulares como em termos cronológicos, servirá como pano de fundo para um melhor enquadramento das informações respeitantes a exemplares de temática religiosa evidenciados nos testamentos da corte portuguesa e que surgem apresentados no ponto seguinte.

\section{IMAGENS, PINTURAS E ALFAIAS RELIGIOSAS}

Os primeiros dados cronológicos que apresentamos sobre este assunto, provêm do acto jurídico de registo de últimas vontades da condessa da Calheta e marquesa de Castelo Melhor ${ }^{21}$, ela que representava o descobridor e capitão donatário da Madeira, João Gonçalves Zarco da Câmara. A titular, D. Mariana de Lancastre, redigiu o seu testamento em 18 de Janeiro de 1688. Lega a diversos membros da sua família objectos de matriz religiosa ${ }^{22}$ :

- A sua irmã, Madre Inês da Santíssima Trindade, que era religiosa no Convento de Santo Alberto, um Cristo grande de marfim, realizado na Índia, que se encontrava no oratório da condessa;

17 Campo Bello, 1935, 127-128.

${ }^{18}$ Filho dos $1 .^{\text {os }}$ condes de Vila Verde, casado com D. Isabel Maria Antónia de Mendonça, filha do $1 .^{\circ}$ marquês de Arronches e $3 .^{\circ}$ conde de Miranda. Zúquete, 1984: II, 281-282.

${ }^{19}$ Filha dos $2 .^{\circ \mathrm{os}}$ marqueses de Angeja, casada com o $4 .^{\circ}$ conde e, já viúvo, $1 .^{\circ}$ marquês de Castelo Melhor, José de Vasconcelos e Sousa Caminha da Câmara Faro e Veiga (1706-1769). Zúquete, 1984: II, 506.

${ }^{20}$ Casado com D. Luísa do Pilar de Noronha (1718-1784), filha dos 5. ${ }^{\text {os }}$ condes dos Arcos. Zúquete, 1984: III, 339.

${ }^{21}$ Zúquete, 1984: II, 467.

22 Arquivo Nacional da Torre do Tombo (A.N.T.T.), Registo Geral de Testamentos, L. ${ }^{\circ}$ 58, ff. 29-33; para estas referências, f. 30. 
- A seu filho, o $3 .^{\circ}$ conde de Castelo Melhor ${ }^{23}$, que fora escrivão da puridade do rei D. Afonso VI e que se encontrava já em Portugal, após anos de exílio em Inglaterra ${ }^{24}$, uma imagem da Padroeira do Reino, a sua Nossa Senhora da Conceição "de vestidos do meu oratorio a qual emagem tenho muita devoção e ma deixo meu avo o Senhor Luis Mendes de Vasconcelos conde que foi de Castello Milhor"25. Havia aqui um sentido de transmissão familiar, em que uma peça de tão especial significado deveria continuar através do legado ao chefe da casa;

- Ao outro filho, D. António de Vasconcelos e Sousa, bispo de Lamego e de Coimbra $^{26}$, a sacra argêntea que possuía no seu oratório e o painel com a representação de Nossa Senhora da Conceição, que lhe legara sua prima a condessa de Figueiró;

- E a seu filho Manuel de Vasconcelos ${ }^{27}$, o Menino Jesus grande do seu oratório.

Desta família há mais uma notícia, procedente do testamento da condessa de Castelo Melhor, D. Maria Rosa de Noronha. Redigido no palácio da Calçada da Glória, em 1752, deixa um relicário ao morgado de Santa Catarina, que havia sido criado quase cinco décadas antes, em homenagem ao apreço da rainha de Inglaterra, D. Catarina de Bragança, pelo acima mencionado $3 .^{\circ}$ conde de Castelo Melhor, que a auxiliou nos momentos difíceis que passou na corte inglesa ${ }^{28}$. Tratava-se de uma relíquia de Santa Mónica, salientando a titular que "tive sempre muito espeçial devoção, e desejo que esta se concerve noz meos descendentez e para memoria diszo lhe deixo esta relíquia vincullada a qual se acha com hum caixilho de fillagrana de pratta com sua autentica" 29 .

Em 1703, a condessa de Pombeiro, D. Luísa Ponce de León, ao redigir o seu testamento revela a importância que dá à peça religiosa que lega, afirmando não poder deixar ao neto, conde de Pombeiro, couza de mais estimação que a sua Nossa Senhora da Conceição. Esta imagem encontrava-se no seu oratório -certamente com todos os seus atavios -, não somente porque era "padroeira da nossa Caza como por ser imagem milagroza e de muita devoção pelo que lhe pesso a queira anexar ao seu morgado como capital delle tendoa primeiro em sua vida

${ }^{23}$ Veio a morrer em 15 de Agosto de 1720. A.N.T.T., Registos Paroquiais, Freguesia de S. José (Lisboa), L. ${ }^{\circ}$ 2-Óbitos, f. 76; Sousa, 1993: 52 (no final da obra vem uma sistematização genealógica com dados actualizados sobre esta casa titular).

${ }^{24}$ Palha, 1883: 62 e ss.

${ }^{25}$ Sobre esta personalidade, que chegou a ser mordomo mor da rainha D. Margarida de Áustria, vd. Zúquete, 1984: II, 502.

${ }^{26}$ Sobre esta figura do clero português, Barbosa, 1727: 320-356.

${ }^{27}$ Canedo, 1945: 2, 8.

${ }^{28}$ Casimiro, 1956: 360, 362 e outras ss.

29 A.N.T.T., Registo Geral de Testamentos, L. ${ }^{\circ} 257$, f. $89 \mathrm{v}$. 
minha filha a dita D. Luiza Antónia Ponçe de Leon por falecimento da qual tha deixo" ${ }^{30}$. Nesta passagem ficam evidenciadas diversas questões, destacando-se a grande devoção que a titular lhe tinha, que a leva a ressaltar o carácter milagroso da imagem, a que acresce o facto de ser padroeira da Casa Pombeiro. Por isso, pede ao neto que a anexe ao morgado, se bem que expressa a vontade de que ficasse previamente em usufruto à tia do titular, em sua vida.

O carácter melagrozo de uma peça de imaginária volta a estar presente no legado (1712) que a condessa de Redondo, D. Madalena Maria de Távora, realiza a D. Violante Henriques, mulher de seu irmão, Tristão de Mendonça. Trata-se de "hum Menino Jesus com seu leito que he a prenda que mais estimo", sendo entregue a sua cunhada pelo amor de que lhe era devedora, solicitando-lhe a estimação devida, por ser aquilo que mais prezava, reforçando, portanto, duas vezes essa ideia no seu testamento ${ }^{31}$.

No testamento de outra condessa de Redondo, D. Maria Antónia de Meneses, observamos uma nova situação, a de legar este tipo de objectos ao marido, Fernando de Sousa Coutinho (1716-1791), $12 .^{\circ}$ conde de Redondo ${ }^{32}$. Para o cônjuge ficariam "duas imagens de Nosso Senhor e São Jozé de vulto, e duas laminas huma de Nossa Senhora da Piedade, e outra da Soledade", que referencia no seu testamento, entre outros bens de distinta natureza ${ }^{33}$. E lega, ainda, dois castiçais de prata para a capela do seu palácio. Como vem descrito no seu inventário, são "castisais de prata com os pes chatos e outavados e moldurados com os balaustres torniados com os seos bocaes para velas todos lizos e com armas", possuindo de peso de prata 4 marcos, 1 onça e 4 oitavas e 1/2, avaliados em $20 \$ 493$ réis $^{34}$.

Outras vezes há apenas uma breve menção a pinturas, indicando o motivo, como sucedeu em 1703, quando a 7. ${ }^{a}$ condessa da Castanheira, D. Ana Ataíde de Castro, legou a seu sobrinho, o Padre António de Ataíde, duas lâminas, cujo tema iconográfico discriminou ${ }^{35}$. Mais tarde, em 1719, a marquesa de Montebelo, D. Luísa Maria de Mendonça e Eça, casada com D. António Félix Machado, deixará a seu filho Félix José a sua lâmina representando o Ecce Hommo que tenho

${ }^{30}$ A.N.T.T., Registo Geral de Testamentos, L. ${ }^{\circ} 113$, f. 89.

${ }^{31}$ A.N.T.T., Registo Geral de Testamentos, L. ${ }^{\circ}$ 131, f. 185.

${ }^{32}$ Filho de D. Diogo de Meneses e Távora, senhor da Patameira e de Caparica, e de sua mulher, D. Maria Bárbara Josefa de Breyner. Zúquete, 1984: III, 200.

${ }^{33}$ A.N.T.T., Registo Geral de Testamentos, L. ${ }^{\circ} 313$, f. $127 \mathrm{v}$.

34 A.N.T.T., Orfanológicos, Letra C, Maço 27, N. ${ }^{\circ}$ 4, f. 32-32v., como se pode verificar na transcrição efectuada por Lina Maria Marrafa de Oliveira, no âmbito do projecto "A Casa Senhorial em Lisboa e no Rio de Janeiro, Séculos XVII, XVIII e XIX”. http://acasasenhorial.org/acs/index.php/en/fontes-documentais-en/inventarios-en/369-condessa-de-redondo-1780 (01-08-2020).

${ }^{35}$ A.N.T.T., Registo Geral e Testamentos, L. ${ }^{\circ} 115$, f. 143v. 
no escaparate, referindo, igualmente, que "todos os mais laminas e paineis de santos que tenho deixo se ponhão no oratorio destas cazas para ornattos delle" ${ }^{36}$.

Pessoas exteriores à família de sangue eram destinatários, por vezes, das últimas determinações do titular quanto a peças de devoção, como se lê no codicilo que acrescentou ao seu instrumento de últimas vontades a condessa de Coculim, D. Maria de Noronha (1731). Assim, a Teotónio de Andrade destinou um painel de muita devoção com a figuração do Senhor dos Passos, tendo ao Padre Frei Vicente de Lima, religioso Jerónimo e prior do Convento da Penha Longa, legado outro com idêntica iconografia ${ }^{37}$.

Os destinatários poderiam ser também igrejas, como sucedeu, em 1753, com a marquesa de Cascais, D. Luísa Maria Helena de Noronha, que lega a Santo António de Cascais a imagem de São Pascoal Bailão. Mas, por outro lado, num gesto de grande bondade, pede a seus filhos, a marquesa do Louriçal e a seu marido, o $1 .^{\circ}$ marquês do referido título, que protejam D. Maria Ana de Noronha, filha de seu marido, o 3. ${ }^{\circ}$ marquês de Cascais, D. Manuel José de Castro Noronha Sousa e Ataíde, legando-lhe um Menino Jesus deitado que está em huma caixa, para além de um relicário do Santo Lenho ${ }^{38}$.

Os mosteiros onde as titulares se encontravam viúvas, como vemos no caso da condessa de Pombeiro, D. Maria Rosa de Noronha, comendadeira ${ }^{39}$ do mosteiro de Santos, podiam chegar também a ser objecto de legados ${ }^{40}$. E, assim, em 1769, esta viúva deixa para Santa Júlia uma lâmina que lhe havia legado Ana Lúcia moça de coro que foi neste mosteiro. O mais importante reside na passagem do testamento em que indica que "Todos os meuz paineiz, e imageñz deixo a ezte mosteiro, e se poram na caza dos Santos Martris ou donde determinar quem governar menos a imagem de Santo António, e a de Santa Anna que estas dezejo se coloque na igreja para honde hira com ornamento (...)"41.

Em 1783, a condessa viúva da Ribeira Grande, D. Margarida Francisca de Lorena, grande devota do Senhor Santo Cristo, de Ponta Delgada ${ }^{42}$, escreve o seu testamento no palácio da Junqueira, em Lisboa. E essa devoção encontra-se espelhada no seu testamento, ao deixar a seu neto, o 6. ${ }^{\circ}$ conde da Ribeira Grande, D. Luís António José Maria da Câmara, uma relíquia do peito para permanecer

36 A.N.T.T., Registo Geral de Testamentos, L. ${ }^{\circ} 152$, f. 32v.

37 A.N.T.T., Registo Geral de Testamentos, L. ${ }^{\circ}$ 197, f. 207.

38 A.N.T.T., Registo Geral de Testamentos, L. ${ }^{\circ} 258$, f. 33v.

39 Sobre as comendadeiras de Santos, Sousa, 1940.

${ }^{40} \mathrm{O}$ mosteiro de Santos, em Lisboa, era o único edifício que, em Portugal, recebia as mulheres dos cavaleiros da Ordem de Santiago. Sobre a tradição das ofertas a mosteiros da Ordem de Santiago, vd. Sousa/Cunha, 2020.

${ }^{41}$ A.N.T.T., Registo Geral de Testamentos, L. ${ }^{\circ} 298$, f. 68.

${ }^{42}$ Sobre a sua ligação ao Senhor Santo Cristo de Ponta Delgada, vd. o estudo Pimentel, 2000: 55-64. 
no seu oratório, enquanto à irmã deste, a condessa de Aveiras, D Leonor Maria da Câmara ${ }^{43}$, ficaria uma lâmina com idêntico motivo iconográfico, porque sei a hade ter com toda a veneração. Não esquece Aires de Sá e $\mathrm{Melo}^{44}$, que por ser seu testamenteiro receberia um painel de Santa Maria Madalena e Santa Marta. Os irmãos da testadora foram alvo, também, de legados de pendor religioso, pois a Manuel de Lorena legou uma imagem de São José, enquanto a Nuno Gaspar de Lorena deveria ser entregue um item referente a dois painéis, representando um Santa Maria Madalena no Deserto e o outro o Senhor da Cana Verde ${ }^{45}$.

A 2. ${ }^{a}$ marquesa de Penalva (e 6. ${ }^{\mathrm{a}}$ condessa de Tarouca), D. Eugénia Mariana Caminha de Meneses, referencia no seu testamento, escrito e aberto em 1788, que ao seu marido, o $6 .^{\circ}$ conde de Vilar Maior, Manuel Teles da Silva ${ }^{46}$, legava um painel pintado por Rafael de Urbino, "por ser a coiza mais precioza que possuo" ${ }^{47}$. O titular, contudo, viria a possuí-lo pouco tempo, pois morreu meses depois. Esta peça surge inventariada nos bens de seu pai, o 1. ${ }^{\circ}$ marquês, D. Estêvão de Meneses (1758-1759), sendo descrita como uma Sagrada Família, com figuras inteiras, bem concervada pintura sobre tábua, "espiciozicima pintura e inextimavel joia do divino talento do grande Raphael de Urbino, foi ditosamente adequerida pelo Excelenticimo Marques de Penalva e estimada, pelo pintor Francisco Vieira (...) em sete mil cruzados”. Foram, pois, lançados no inventário 2:800\$000 réis, uma soma que, mesmo assim, se distanciava em muito de uma pintura referenciada como de Dürer, que constava haver pertencido ao imperador Carlos V da Alemanha, e a que foi atribuído o valor de $800 \$ 000$ réis $^{48}$. A obra de Rafael tratar-se-ia de uma pintura de excepcional qualidade - cuja localização e história posterior desconhecemos -, sendo-lhe atribuído um valor muito significativo para a época, sinal da relevância que Francisco Vieira, mais conhecido como Vieira Lusitano $^{49}$, lhe conferiu. O inventário da galeria de pintura dos marqueses de Penalva, em 1758, foi dado a conhecer por Silva Tarouca em 1945, referindo ambas as pinturas ${ }^{50}$.

${ }^{43}$ Filha dos $5 .^{\circ s}$ condes da Ribeira Grande e casada com o $7 .^{\circ}$ conde de Aveiras (e 2. marquês de Vagos), D. Nuno da Silva Telo e Meneses, Zúquete, 1984: III, 457.

${ }^{44}$ Sobre este personagem, vd. Beirão, 1934.

45 A.N.T.T., Registo Geral de Testamentos, L. ${ }^{\circ} 321$, f. 214v.

${ }^{46}$ Era seu primo, filho dos 5. ${ }^{\text {os }}$ condes de Vilar Maior e 4. ${ }^{\text {os }}$ marqueses de Alegrete (1727-25 de Fevereiro de 1789). Zúquete, 1984: III, 114.

47 A.N.T.T., Registo Geral de Testamentos, L. ${ }^{\circ} 327$, f. 4.

48 A.N.T.T., Orfanológicos, Letra M, Maço 173, N. ${ }^{\circ}$ 4, ff. 33-34, transcrição do inventário efectuada por Lina Maria Marrafa de Oliveira, no âmbito do Projecto "a Casa Senhorial em Lisboa e no Rio de Janeiro, Séculos XVII, XVIII e XIX”. http://acasasenhorial.org/acs/index.php/pt/fontes-documentais/inventarios/412-marques-de-penalva-1758-1759\#_ftn1 (23-11-2019).

${ }^{49}$ Sobre este importante pintor setecentista português, vd. Arruda:1999.

50 Tarouca, 1945: 6. 
As últimas menções a objectos religiosos nos testamentos de que dispomos nesta selecção de instrumentos de últimas vontades datam do ano seguinte, 1789, provindo do registo de últimas vontades do $4 .^{\circ}$ conde de S. Miguel, D. Álvaro José Xavier Botelho. Este documento possui a curiosidade de referenciar o oratório "nas cazas de sima" que o titular havia mandado fazer "Para melhor comodo da minha familia", apesar de o seu palácio possuir uma ermida. Referencia uns painéis, pertença do fideicomisso, mas outras peças são de sua propriedade, como os santos e a urna. Assim, menciona as peças que deixa à Caza: a imagem de São José, a do Santo Cristo, a de Nossa Senhora dos Remédios e a de São Miguel. Estas duas tinham especial significado para D. Álvaro, pois se a primeira era a padroeira da família, a de São Miguel, que possuía insígnias de prata, era "o orago da nossa Caza, e o primeiro que com lugar distincto se colocou nos seus altares", pelo que determinava se vinculasse ao morgado. Solicitava, ainda, a sua nora, D. Ana Isabel de Portugal Correia de Lacerda Coronel de Sá e Meneses, casada com seu filho, Fernando Xavier Botelho de Távora, $5 .^{\circ}$ conde e falecido em vida do pai ${ }^{51}$, "que tracte a este altar, e a estes sanctos com aquelle culto que se pode esperar da sua religioza piedade, não se servindo d'aquella caza nunca para uzo profano". As galhetas de prata seriam entregues ao testamenteiro para integrarem o inventário por morte deste titular.

Existem outras referências sobre a Ermida de Nossa Senhora da Conceição e a indicação a duas peças no oratório: um Santo António, grande, destinado a D. Ana Joaquina da Silveira, e uma imagem de Nossa Senhora de Ales, que seu bisavô, o 1. ${ }^{\circ}$ conde de S. Miguel, Francisco Nuno Álvares Botelho (1627-1687) ${ }^{52}$, havia trazido de Castela. Esta escultura encontrava-se guardada num caixão e sem culto, tendo sido a mãe do testador, a condessa D. Juliana de Lancastre ${ }^{53}$ que "lho restituio no seu altar, não sei a quem pertence, mas pela posse immemorial pertence ao oratorio da Caza onde fica, e deve ficar" ${ }_{54}$.

O testamento apresenta umas últimas indicações quanto a painéis que eram de propriedade de D. Álvaro José Xavier Botelho e se encontravam em Rilhafoles, designadamente representando São Pedro e São Paulo (dois), o Senhor da Paciência (dois), o Senhor pregandose na Cruz, Nossa Senhora do Pópulo, o Menino Jesus e um outro de Nossa Senhora do Carmo ${ }^{55}$.

${ }^{51}$ Zúquete, 1984: III, 340.

52 Zúquete, 1984: III, 339.

${ }^{53}$ Dama do Paço e casada com o $3 .^{\circ}$ conde de S. Miguel, filha dos $3 .^{\text {os }}$ condes de Unhão. Zúquete, 1984: III, 339.

${ }_{54}$ A.N.T.T., Registo Geral de Testamentos, L. ${ }^{\circ} 328$, f. $2 \mathrm{v}$.

${ }^{55}$ A.N.T.T., Registo Geral de Testamentos, L. ${ }^{\circ} 328$, f. 4. Existe ainda a menção a diversas pinturas, designadamente vinte e oito painéis de diferentes tamanhos, com molduras douradas, e outros vinte e quatro painelinhos, com molduras de pau santo, sendo quatro maiores e vinte mais pequenos (f. 4). 
Uma última referência ao testamento do $1 .^{\circ}$ marquês de Angeja e $2 .^{\circ}$ conde de Vila Verde, D. Pedro António de Noronha, o vice-rei da Índia e do Brasil que, em 1731, determinou legar a sua nora e sobrinha, a condessa de Vila Verde, D. Luísa Josefa de Meneses ${ }^{56}$, uma cruz de Santo Lenho que havia pertencido a uma custódia-relicário, sinal claro "do grande amor, e veneração que tenho a sua pessoa, e agradecimento da bôa criação que tem dado a meus netos, e dezejara ser senhor de muito para the deixar" ${ }^{\text {57. }}$ O apreço pelas relíquias atingiu nos séculos XVII e XVIII um momento particularmente importante, como também se pode verificar através de alguns dados presentes nos testamentos recolhidos, registando-se a sobrevivência de numerosos exemplares montados em estruturas de madeira e de prata, que assumiram distintas formas.

Deparamo-nos, ao longo deste ponto, com uma alusão a frequentes representações iconográficas religiosas que espelham algumas das tipologias que chegaram até à actualidade em quantidades dignas de apreço. Entre elas, as imagens de Nossa Senhora da Conceição ${ }^{58}$, Padroeira do Reino, e do Senhor Santo Cristo, com larga tradição nas ilhas açorianas, mas também os crucifixos com a imagem de Cristo em marfim, provenientes do Oriente ${ }^{59}$ ou de execução portuguesa, e até os delicados Meninos Jesus colocados em seus leitos ${ }^{60}$, que tanto deleite provocavam nas suas proprietárias. E, diga-se, regista-se uma indicação dos vários oragos das casas titulares, como foi possível evidenciar em diversos casos, designadamente pela condessa de Pombeiro e pelo conde de S. Miguel. À escultura vinha também juntar-se a pintura de temas ou figuras religiosas sobre suporte de madeira ou metal.

Estes legados tornam-se provas de uma generosidade autêntica, estabelecendo as últimas vontades relativas a peças religiosas, em que privilegiavam, em primeiro lugar, os filhos e filhas, mas, sobretudo quando não havia descendentes directos, outros familiares e, igualmente, religiosos que lhes eram próximos. Não esqueceram, algumas vezes, as igrejas da sua predilecção, como certos casos referenciados supra evidenciam.

\section{NOTAS FINAIS}

Como se torna perceptível ao longo deste estudo, a referência a esculturas, pinturas e alguns objectos de matriz religiosa nos testamentos dos titulares da corte de Lisboa no período em consideração, que vai dos finais de Seiscentos a

\footnotetext{
${ }^{56}$ Filha dos 4. ${ }^{\text {os }}$ condes de Tarouca. Zúquete, 1984: III, 282.

57 A.N.T.T., Registo Geral de Testamentos, L. ${ }^{\circ} 198$, f. 155.

${ }_{58}$ Por exemplo, Coutinho, 1959 ou Brandão, 1988.

59 Nomeadamente, Távora, 1983, 97-125; A expansão ... (1991), 136-154.

${ }^{60}$ Falcão, 2000, 2, 138-143.
} 
finais da centúria seguinte, evidencia a religiosidade no interior doméstico e a particular devoção a determinadas invocações.

O apreço por certas imagens, a que tinham uma forte ligação emocional ou, até, a evocação de uma referência ligada à sua Casa ou aos seus antepassados, constituem outros aspectos patentes em alguns dos instrumentos de últimas vontades. Esta dimensão associada ao devocional, por um lado, e ao simbolismo familiar, por outro, representa valores da aristocracia do Antigo Regime, ainda mais ressaltados quando o que estava em causa era a relação da sua Casa a esta vertente de protecção sobrenatural, de que as imagens seriam um veículo privilegiado.

A escolha dos destinatários (pessoais ou institucionais) dos objectos devocionais enquadra-se nos princípios e valores do Antigo Regime, havendo sempre um especial significado na referida indicação, pois elencar esta ou aquela peça, tendo por legatário esta ou aquela pessoa, ou instituição, adquire uma projecção referencial que não pode, caso a caso, deixar de ser enquadrada.

Umas vezes imagens, outras pinturas ou peças de ourivesaria religiosa, outras ainda relíquias em diversos suportes, a expressa menção num testamento permite observar a relevância de uma forte religiosidade, tanto no interior doméstico como nas igrejas da sua maior devoção. Todos estes comportamentos e as crenças particulares, evidenciadas sobretudo nos testamentos femininos, representam o mais íntimo das vivências de alguma da nobreza titulada da corte portuguesa entre finais de Seiscentos e os últimos tempos do século XVIII.

Fecha de recepción: 30 de septiembre de 2020.

Fecha de aceptación: 2 de mayo de 2021.

\section{BIBLIOGRAFIA}

Arruda, Luísa Capucho (1999): Francisco Vieira Lusitano (1600-1783). Uma época de desenho. Lisboa: Faculdade de Belas-Artes da Universidade de Lisboa. Dissertação de doutoramento.

Barbosa, D. José (1727): "Memorias do Collegio Real de S. Paulo da Universidade de Coimbra, e dos seus collegiaes e porcionistas". Em: Silva, Manuel Telles da (ed.) - Collecçam dos documentos e memorias da Academia Real da Historia Portugueza (...). Lisboa: Oficina de José António da Silva, pp. 320356.

Beirão, Caetano (1934): D. Maria I (1777-1792): Subsídios para a revisão da História do seu reinado. Lisboa: Empresa Nacional de Publicidade.

Brandão, Domingos de Pinho (1988): Algumas das mais preciosas e belas imagens de Nossa Senhora existentes na diocese do Porto. Porto: Diocese do Porto. 
Campo Bello, Conde de (D. Henrique) (1935): Governadores-gerais e vice-reis do Brasil. [S. 1.]: Divisão de Publicações e Biblioteca; Agência Geral das Colónias.

Canedo, Fernando de Castro da Silva (1945; 1946): A descendência portuguesa de El-rei D. João II. Lisboa: Edições Gama, I-II, 1945; III, 1946.

Casimiro, Augusto (1956): D. Catarina de Bragança: rainha de Inglaterra, filha de Portugal. Lisboa: Fundação da Casa de Bragança; Portugália Editora.

Coutinho, B. Xavier (1959): Nossa Senhora na Arte. Porto: [s. n.].

A expansão portuguesa e a arte do marfim (1991). Lisboa: Comissão Nacional para a Comemoração dos Descobrimentos Portugueses.

Falcão, José António (2000): “Menino Jesus no berço e anjo". Em: Falcão, José António (ed.) - Entre o céu e a terra: arte sacra na diocese de Beja. Beja: Departamento do Património Histórico e Artístico da Diocese de Beja, II, pp. 138-143.

Leal, Miguel Montez (2017): “O programa decorativo azulejar do pintor Pereira Cão para o Pátio do Palácio da Rosa, propriedade dos Marqueses de Castelo Melhor". Em: Actas do $4{ }^{\circ}$ Congresso Internacional Casa Nobre um Património para o Futuro. Arcos de Valdevez: Município de Arcos de Valdevez, 2, pp. 1029-1039.

Martins, Rocha (1940): Os grandes vultos da Restauração em Portugal. Lisboa: Empresa Nacional de Publicidade.

Monteiro, Nuno Gonçalo (1998): O crepúsculo dos Grandes (1750-1832). [S. 1.]: Imprensa Nacional - Casa da Moeda.

Palha, Fernando (1883): O conde de Castel Melhor no exílio: ensaio biográfico. Lisboa: Imprensa Nacional.

Pimentel, António Filipe (2000): "Percursos do barroco nos caminhos do Atlântico: o culto e o tesouro açoriano do Senhor Santo Cristo dos Milagres". Em: Oceanos. 43 (Jul.-Set.), pp. 55-64.

Sousa, Ana Cristina/Cunha, Mário (2020): "Molher que foy... Las donaciones femininas a las iglesias de la Orden Militar de Santiago, en Portugal, en los siglos XV y XVI”. Em: Res Mobilis: Revista internacional de investigación en mobiliario y objetos decorativos. 9 (10), pp. 52-69.

Sousa, Gonçalo de Vasconcelos e (1993): Subsídios para o levantamento do Património Construído de Almendra. Porto: Câmara Municipal de Vila Nova de Foz Côa.

Sousa, Gonçalo de Vasconcelos e (1997): "Instrumentos de vontade para além da morte: testamentos de ourives de ouro portuenses (1805-1837)”. Em: Poligrafia. 6, pp. 75-87.

Sousa, Gonçalo de Vasconcelos e (2011): "Legados humanos e devocionais: Artes Decorativas nos testamentos lisboetas da segunda metade de Setecentos". Em: Sousa, Gonçalo de Vasconcelos e (ed.): Matrizes da investigação em Artes Decorativas II. Porto: UCE-Porto; CITAR, pp. 11-42. 
Sousa, Tude Martins de (1940): “Comendadeiras de Santiago”. Em: Arquivo Histórico de Portugal. 4. Separata.

Tarouca, J. Silva (1945): Inventário das pinturas, que em 1758 possuia a casa dos marqueses de Penalva. Lisboa: Instituto para a Alta Cultura; Centro de Estudos de Arte e Museologia.

Távora, Bernardo Ferrão de Tavares e (1983): Imaginária-luso-oriental. Lisboa: Imprensa Nacional - Casa da Moeda.

Zúquete, Afonso Eduardo Martins (ed.) (1984): Nobreza de Portugal e do Brasil. 2. ${ }^{a}$ ed. Lisboa: Editorial Zairol, II-III. 